\title{
Orientación epistemológico-contable en la Fundación Universitaria del Área Andina
}

\author{
Epistemological-contable orientation in the university "Fundación Universitaria del Área \\ Andina"
}

BARON, Camilo A. ${ }^{1}$

ARIZA, Efrén D. ${ }^{2}$

\section{Resumen}

El objetivo de este documento es indagar la conceptualización que tienen los estudiantes del programa de contaduría pública de la Fundación Universitaria del Área Andina, frente a los fundamentos teóricos que adquieren los estudiantes en el pregrado, respecto a su profesión. La metodología aplicada es de campo con un enfoque cuantitativo, aplicando encuestas a los estudiantes del programa que permitan medir la orientación teórica del programa. Como principal resultado se obtiene que la mayoría de los estudiantes conciben la contabilidad como una técnica.

Palabras clave: partida doble, epistemología, teoría científica.

\begin{abstract}
The objective of this document is to indegrate the conceptualization of students of the public accounting program of the University Foundation of the Andean Area, in the face of the theoretical foundations acquired by students in the undergraduate, regarding their profession. The methodology applied is field with a quantitative approach, applying surveys to the students of the program that allow to measure the theoretical orientation of the program. As the main result it is obtained that most students conceive of accounting as a technique.

Keywords: double heading, epistemology, scientific theory.
\end{abstract}

\section{Introducción}

Los programas de contaduría pública del país enfocan la enseñanza mayoritariamente hacia la práctica de la disciplina, concibiéndola como una técnica enfocada al hacer y no una ciencia que se esfuerza por comprender el ser; sin embargo, en la academia se habla de investigación contable y se realizan publicaciones, eventos y discusiones en torno a la profesión. El presente artículo no pretende dar una postura hacia una de las distintas corrientes que se han planteado en el mundo en busca de la esencia y el concepto epistemológico de la contabilidad, sino que se plantea medir a través de la aplicación del instrumento a los estudiantes, el enfoque

\footnotetext{
1 Estudiante de Contaduría Pública (octavo semestre), semillerista del grupo de investigación QUIPUS. Fundación Universitaria del Área Andina. cbaron8@estudiantes.areandina.edu.co

2 Economista Universidad Nacional de Colombia, Egresado Maestría en Sociología Universidad Nacional de Colombia, Magister en Filosofía Latinoamericana Universidad Santo tomas, PH.D @ en Filosofía Universidad Santo Tomas. Docente Fundación Universitaria del Área Andina. Líder Grupo de investigación QUIPUS. Fundación Universitaria del Área Andina. eariza10@areandina.edu.co
} 
que se les da en materia epistemológica durante su formación o si por el contrario el programa de contaduría pública carece de una postura clara frente al tema central de esta investigación.

Por dar un ejemplo de la poca importancia que se le da a la fundamentación teórica y a la historia de la contabilidad durante el pregrado, es preciso afirmar que la mayoría de los estudiantes conciben a Luca Pacioli como el padre y creador de la contabilidad, descociendo que "si bien Pacioli, es padre de la partida doble ${ }^{1}$ tradicional, no puede considerársele como el primer autor contable" (Suárez Pineda, 2008, p. 38) pues algunos autores afirman que la contabilidad data desde que el hombre tuvo la necesidad de controlar sus recursos, esto sucede aproximadamente en el año 8000 a.C. En la primera parte del artículo se encuentra el estado del arte, donde se pretende indagar en investigaciones realizadas con anterioridad que han asumido una postura frente a la disyuntiva que existe frente al tema central. En la segunda parte del artículo se encontrará con el marco conceptual y la metodología aplicada para llevar a cabo la investigación. Por último, el lector se encontrará con los resultados de la investigación, producto del instrumento aplicado y las conclusiones.

\section{Estado del arte y revisión de la literatura}

Para Casal y Viloria (2007) la contabilidad debe mirar hacia un cambio paradigmático que permita superar las limitaciones del proceso histórico contable, pues la contabilidad data su aparición desde que el hombre tuvo la necesidad de cuantificar y anotar, sin embargo, aunque sus antecedentes se pueden encontrar desde la época de los sumerios, aproximadamente 8000 a.C, no es sino hasta el año 1494 d.C que Luca Pacioli expone los métodos contables y desde entonces quedan impresos los fundamentos de la partida doble. Luego con el positivismo se da una visión más realista sobre la dinámica de los estados financieros, esto interrumpe la visión que reduce la contabilidad a la ecuación patrimonial: Activo=Pasivo+Patrimonio, que limita la profesión a la obtención de cifras sin contexto; con los años se ha cambiado la visión de la esencia contable, pues "primero se desarrolló la técnica, hasta ahora se ha instaurado un proceso de teorización, este lentísimo proceso de cambio de una actividad práctica a una actividad teórica indica que es necesario profundizar en la búsqueda de una metodología contable" (Mancilla \& Quispe, 2017, p. 6)

Según Cañibano, Tua Pereda, y López (1985) todos los sistemas contables, aun cuando cuentan con reglas y manifestaciones diferentes, tienen una serie de rasgos que permiten englobarlos bajo un común denominador, por esto en la epistemología contable es posible distinguir "Una teoría general que analiza los rasgos esenciales y comunes de todos los sistemas contables, formalizando y generalizando las características de la ciencia contable" (Cañibano, et al., 1985, p. 300)

Generalmente, en el entorno académico mundial, cuando se habla de Teoría Contable está haciéndose referencia a los corpus ontológicos, epistemológicos y metodológicos que pretenden explicar-comprender, de forma sistemática y racional, las prácticas, procesos, procedimientos, técnicas, tecnologías e, incluso, las reglas contables. Algunas teorías trascienden el espíritu descriptivo, abstracto, universalista y funcional, para relacionar el rol contable con su entorno social, cultural, institucional y político (Macintosh \& Hopper, 2005). Citado por (Gómez, 2008, pág. 3)

Para Gómez (2004) en el ámbito internacional investigativo existen dos corrientes u orientaciones que compiten por la fundamentación teórica de la contabilidad. El primer programa de investigación entiende la contabilidad como un sistema de información, esta visión entiende que la contabilidad aplica una serie de procedimientos para reflejar a través de los estados financieros sobre la realidad económica de las organizaciones y su estructura

${ }^{1}$ Incluso Suarez Pineda (2012) señala que el verdadero creador de la partida doble fue Benedetto Cotrulli anterior a Pacioli. 
es funcional con los usuarios que direccionen la información requerida. El segundo, llamado nueva contabilidad, plantea que "la contabilidad es un poderoso mecanismo que interpreta, mide y representa la circulación" (Gómez, 2004, p. 120) específicamente de la circulación de riqueza y rentas; "los académicos, investigadores y practicantes contables deben reflexionar en torno a los problemas epistemológicos, ontológicos y metodológicos que se presentan en la construcción de conocimiento socialmente útil" (Machado, 2012, p. 221-222). A diferencia de Gómez (2004), para Carrizo y León (2007) el concepto epistémico de la contabilidad está dividida en tres corrientes diferentes; en primer lugar hay quienes afirman que es una ciencia factual dedicada a la compresión de la realidad por medio de procedimientos técnicos, en segundo lugar están quienes afirman que es una tecnología social que mide la realidad y por último, están los autores que no desarrollan concepciones epistemológicas, pero sus conceptos apuntan a señalar que la contabilidad es una técnica. En oposición a los autores mencionados con anterioridad García (2009) señala que la epistemología contable enfrenta riesgos muy similares a los de las ciencias sociales en general, pues, aunque existen publicaciones en revistas científicas importantes en Colombia alrededor de este tema, los autores usualmente carecen de fundamentos filosóficos, por ende hay falta de compresión a la hora de valerse de la epistemología para abordar el pensamiento contable; esto repercute en un traslado erróneo y descuidado de conceptos filosóficos a la profesión contable.

Fruto de algún tipo de investigación, en el contexto nacional e internacional, algunas consideraciones expresan que la contabilidad se había dedicado en exclusiva a diseminar por el mundo económico y social, una práctica, utilitaria y pragmática que reduce las posibilidades de avance a partir de un interés particular dirigido a ejercer controles sobre las propiedades que generan algún tipo de riqueza. (González, 2014, pág. 173)

Entre los investigadores contables existe una discrepancia frente al concepto o la naturaleza de la contabilidad; según Torres y Lam (2012) quienes sostienen que es una técnica que se ocupa de actividades económicas, por ende, se apoya en el marco teórico de dicha ciencia, así provee información que necesita la actividad productiva y financiera. Pero para otros investigadores de la es una ciencia que "genera conocimientos conexos entre la economía y las finanzas, cuantifica el patrimonio público o privado, determina las pérdidas y ganancias de las entidades, y en consecuencia es ciencia, pero está aletargada por falta de investigación" (Torres \& Lam, 2012), el autor sostiene que está dicotomía se debe en gran parte a que en los programas de pregrado no se alienta al estudiante por temas de investigación, sino que se hace más énfasis en la parte normativa, dando así al estudiante una educación tubular que se limita a enseñar procedimientos de carácter técnico. En consonancia con Torres y Lam, Ordoñez (2008) señala que existe un adiestramiento contable del cual la profesión debe apartarse, pues:

Este adiestramiento no le permite al estudiante considerar las consecuencias de su proceder, tampoco preverlas; la instrucción se basa en el hacer y no en el pensar lo que se hace. La repetición entrena al estudiante en la realización de un cierto tipo de actividad, lo especializa o lo vuelve experto. Dicha aptitud, a la larga, si no se relaciona con el desarrollo de la capacidad de pensar lo que se hace, aísla al experto, lo parcela en un determinado campo y difícilmente le permite participar de la comprensión de otros procesos afines o comunes. (Ordoñez, 2008, p. 118)

Geba (2004) afirma que es necesario realizar una ruptura epistemológica comprendiendo que es necesario romper con las formas mecánicas para producir conocimiento contable, luego de esta ruptura se pueden replantear conceptos en busca de una teoría contable. En consonancia con lo anterior Ariza y Villasmil (2014) hacen un llamado a las universidades y en especial a los programas de contaduría pública, para realizar un cambio de las metodologías aplicadas en los programas de pregrado; este cambio debe estar enfocado desde un ámbito investigativo, que permita a la comunidad académica, en especial los estudiantes, conocer los fundamentos y axiomas de la profesión contable antes de mirar hacia la práctica. De esta manera se promueve el avance de la contabilidad como ciencia, ya que en la actualidad la enseñanza de la contabilidad tiene un enfoque pragmático 
sobrecargado de ejercicios prácticos y escasa teoría contable. Uno de los principales problemas que tiene por superar la investigación contable es el hecho que "se sigue pensando que la investigación no ayuda a desarrollar habilidades y competencias laborales y por ende se le desprecia y se le acusa de no "agregar valor" a la formación profesional" (Rueda, 2007, p. 123) .Por su parte Casal, Viloria, y Zaá (2005) afirma que la contabilidad debe replantearse el conjunto de elementos fundamentales y con esto dejar de ser una técnica dedicada al registro y simple análisis de la información, para pasar a ser una compleja ciencia, esto permitiría intercambios de conocimientos útiles con otras diciplinas, que aporten a la construcción un pensar contable.

De la Rosa Leal (2016) afirma que en la profesión contable hay un discurso que define los estados contables como el reflejo fiel de una realidad económica, pero existen vacíos conceptuales en la forma en que la profesión contable aborda la riqueza medioambiental, esto conlleva a que existan vacíos en la representación contable y falta de alcance en la revelación para sucesos que son reales y generan impactos negativos o positivos para el medio ambiente por parte de una organización.

Según Mejía (2004) Richard Mattessich siendo el autor que más contenido ha aportado al tema de epistemología y pensamiento contable, a partir de diferentes publicaciones ha concebido a la contabilidad como una ciencia aplicada, entendiendo que una ciencia pura radica en la relación causa efecto, mientras que una ciencia aplicada busca la relación que existe entre los fines y medios; para Mattessich la contabilidad "persigue un fin práctico como es el medir los factores de riqueza en una entidad económica, el flujo de la riqueza económica en cuanto a su creación, distribución y destrucción" (Mejía, 2004, p. 157). Afirma Mejía (2004) que en el caso de la contabilidad no es posible definir con exactitud si esta es de carácter positivista o normativista, sino que se complementan ambos factores, por esto el desarrollo de una teoría contable requiere el tratamiento de una metodología flexible que permita el tratamiento adecuado de los diversos objetivos.

\section{Marco teórico}

Una buena síntesis sobre los ámbitos de la disciplina contable, que permitiría cerrar la revisión de literatura, es la que realiza Gómez (2004), cuando identifica que existen tres ámbitos en la formación de contadores públicos:

- Ámbito Técnico que hace referencia a las prácticas y procedimientos cotidianos del profesional de la Contaduría.

- Ámbito Tecnológico que hace referencia básicamente a las normas que delinean el que hacer del contador, muy en boga contemporáneamente a propósito de la convergencia de Colombia a Normas internacionales.

- Ámbito Teórico que exige un abordaje crítico y un diálogo interdisciplinar con la economía, la ciencia política, la sociología, la filosofía y la ecología principalmente.

Se puede evidenciar que, al ser la contabilidad financiera, de gestión y de costos; los paradigmas dominantes; la mayoría de los programas de contaduría pública hacen énfasis en los ámbitos técnico y tecnológico, es decir se interpreta la contabilidad como una técnica; máximo como una disciplina técnica; entre tanto el ámbito teórico es poco trabajado y en ese sentido, no se conocen posturas heterodoxas como la contabilidad social, la biocontabilidad, las contracuentas y los análisis que interpretan a la contabilidad en clave foucaultiana como tecnología de gobierno o dispositivo de poder, sencillamente no se conocen, no se discuten, ni se valoran.

Mejía, Mora, y Montes (2013) señalan que la contabilidad tiene tres dimensiones:

- Como predominante la contabilidad de carácter económico y financiero, abarca lo relacionado a las normas internacionales NIIF y NIC. Incluso en algunos autores históricamente consideraron que la contabilidad, es una disciplina que se desprende de la economía. Con desarrollos actuales de la contaduría, han permitido que se tenga una conceptualización de carácter autónomo. 
- La dimensión social que computa información en términos no necesariamente monetarios, sino considerando componentes del todo social o comunitario. También mide e informa sobre los costes o beneficios para la sociedad de las actividades desarrolladas por la empresa.

- La dimensión ambiental que evalúa contablemente las acciones de acciones ambientales identifica costes e impactos ambientales efectuados por las actividades de la empresa y elabora informes ambientales separados.

\section{Metodología}

La presente investigación es de carácter documental en su estado del arte, donde se analizan los avances de otros investigadores en cuanto a epistemología y pensamiento contable y sus problemáticas desde la investigación; en el marco teórico se conceptualiza la filosofía positivista de Comte y el pensamiento contable de Mattessich.

La parte de campo es de enfoque cuantitativo, allí se toma como población a los estudiantes del programa de contaduría pública (modalidad presencial) de la Fundación Universitaria del Área Anadina (sede Bogotá); dicha población es de 890 estudiantes, se calcula una muestra representativa con un nivel de confianza de $95 \%$ y un margen de error de 5, lo que da como resultado una muestra de 269 estudiantes, para efectos prácticos de la investigación se aproxima a 270; a esta muestra se les aplicó el instrumento plasmado en el anexo número 1, el cual consiste en una encuesta con 13 preguntas cerradas y una pregunta abierta; este instrumento tiene como objetivo identificar la inclinación de los estudiantes en cuanto a una de las corrientes de pensamiento contable que menciona el profesor Gómez (2004).

Para la tabulación de los datos y la elaboración de las gráficas que se plasman en los resultados de la investigación, se utilizó el programa estadístico STATA, en su versión 15.1

\section{Resultados}

\section{1 ¿Qué concepto epistemológico de contabilidad tienen los estudiantes?}

Como señala Gómez (2004) a nivel mundial existen principalmente dos corrientes alrededor de la epistemología contable. Por un lado, existen autores sostienen que es una ciencia dedicada a la compresión de la realidad; por otro lado, otros autores afirman que la contabilidad es una técnica que mide recursos económicos. Con la presente investigación no se pretende dar una postura hacia una de las dos corrientes que existen a nivel mundial sobre epistemología contable, sino indagar hacia cuál de estas se inclinan los estudiantes de la Fundación Universitaria del Área Andina. En tal sentido se formularon las preguntas 1, 2 y 5 del instrumento en el gráfico 1 se exponen las respuestas a estos interrogantes:

Al analizar el gráfico 1 se hace evidente como la mayoría de los estudiantes aún conciben la contabilidad como una simple teneduría de libros, pues cuando se le preguntó a los estudiantes: a lo que se dedica la contabilidad, el $81,48 \%$ respondió que la contabilidad se dedica a cumplir las NIIF y NIC, mediante los procedimientos previamente establecidos, mientras que solo el $18,52 \%$ de los encuestados, respondieron que la contabilidad identifica y resuelve problemas mediante la aplicación de conocimientos propios. 
Gráfico 1

Función de la contabilidad

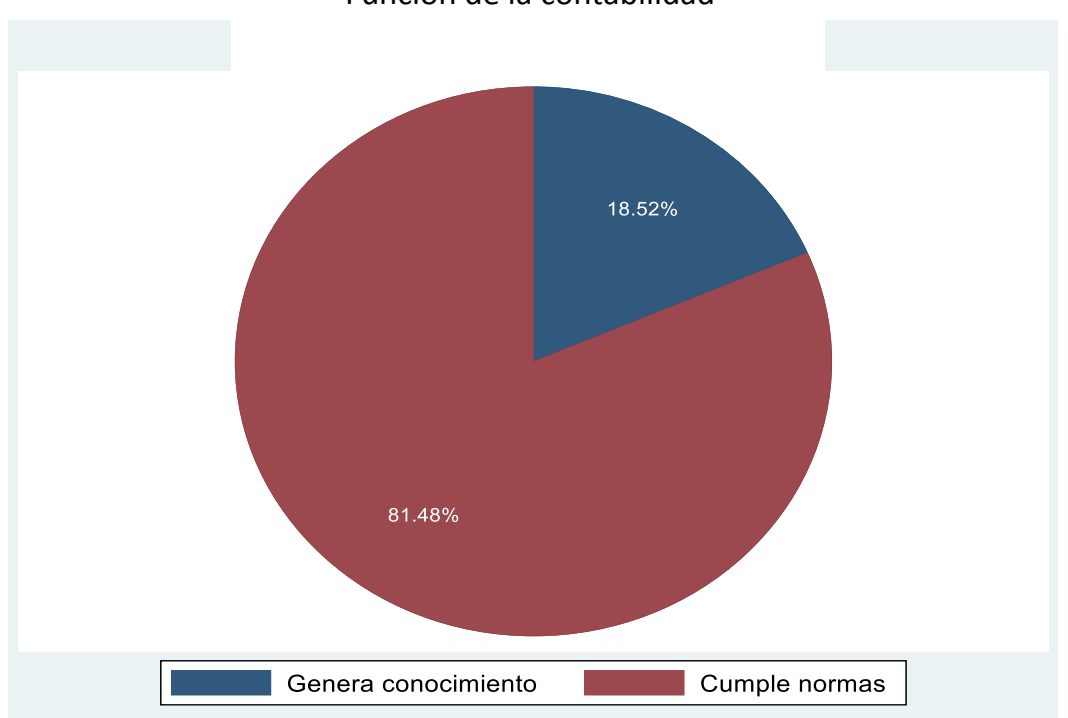

Fuente: Elaboración propia en base al instrumento aplicado

Para no quedarse con la primera aproximación mediante una sola pregunta, también se consultó con los estudiantes si consideraban que la contabilidad es:

- Una ciencia, dedicada a la comprensión de la realidad, por medio de procedimientos técnicos.

- Una técnica social que mide la realidad.

- Una técnica para medir recursos económicos.

En el gráfico 2 se plasman los resultados de la pregunta 2, segregando por las respuestas que se obtuvieron en la pregunta número uno.

\section{Gráfico 2}

Función segregada por concepción de la contabilidad

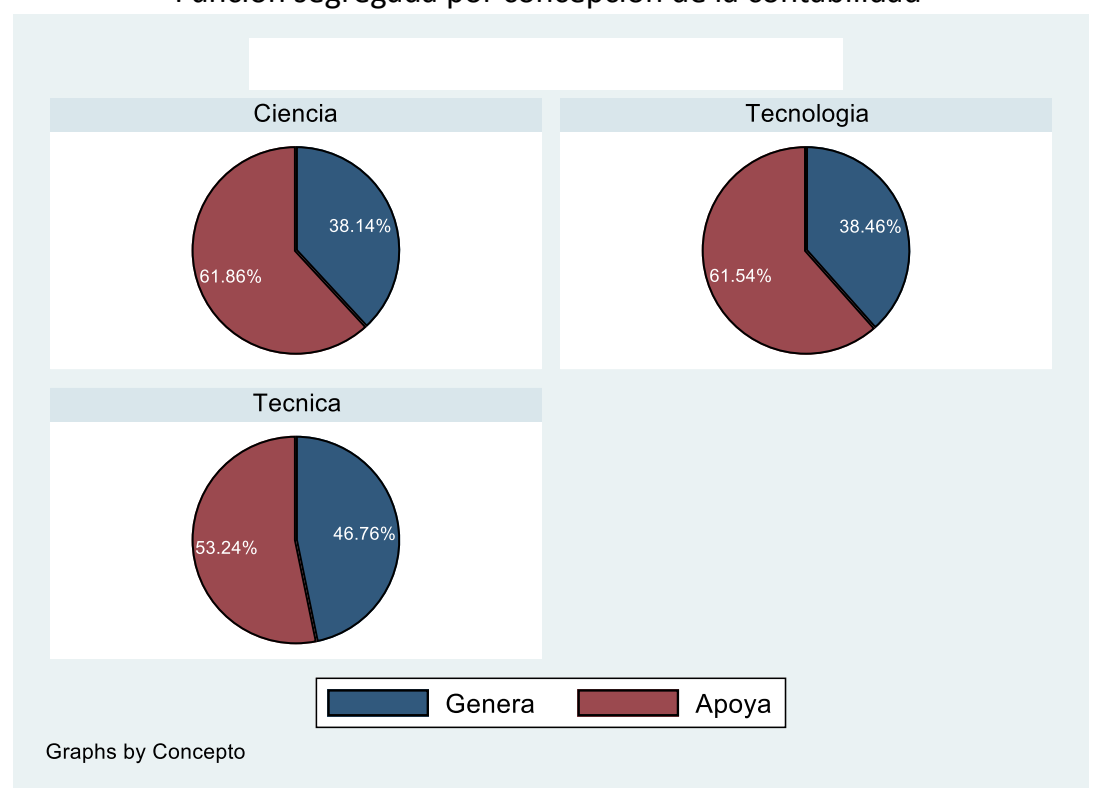

Fuente: Elaboración propia en base al instrumento aplicado 
Lo que se esperaría como resultados a la gráfica 2, es que quienes afirman que la contabilidad es una ciencia a su vez coincidan en que la profesión genera conocimientos y que, quienes afirman que es una técnica, afirmen que la profesión se apoya en actividades económicas para proveer información. Sin embargo, los resultados arrojados son contrarios a esta hipótesis, pues quienes afirman que la contabilidad es una ciencia, en su mayoría (61,86\%) afirma que la contabilidad se apoya en actividades económicas para proveer información; mientras que entre quienes consideran que la contabilidad es una técnica, si bien el 53,24\% de los estudiantes afirma lo mismo, la brecha es claramente menor entre ambos resultados.

Como se mencionó con anterioridad, los resultados arrojados por el instrumento en cuanto las gráficas 1 y 2 , fueron los que se esperaban según la hipótesis planteada. Por lo cual se plantearon las preguntas tres y cuatro, con el objetivo de indagar una de las posibles causas de la concepción epistemológico contable que tienen los estudiantes. Allí se preguntó a los estudiantes si durante su formación académica se les ha hablado de epistemología contable, a lo que solo el $40 \%$ de los estudiantes respondió de forma afirmativa; adicionalmente, cuando se preguntó a los estudiantes por el concepto de epistemología el 60\% de ellos respondió de forma correcta. En el gráfico 3 se observan los resultados de la pregunta número cuatro, segregado por los resultados de la pregunta tres:

\section{Gráfico 3}

Concepción de epistemología, segregado por formación académica

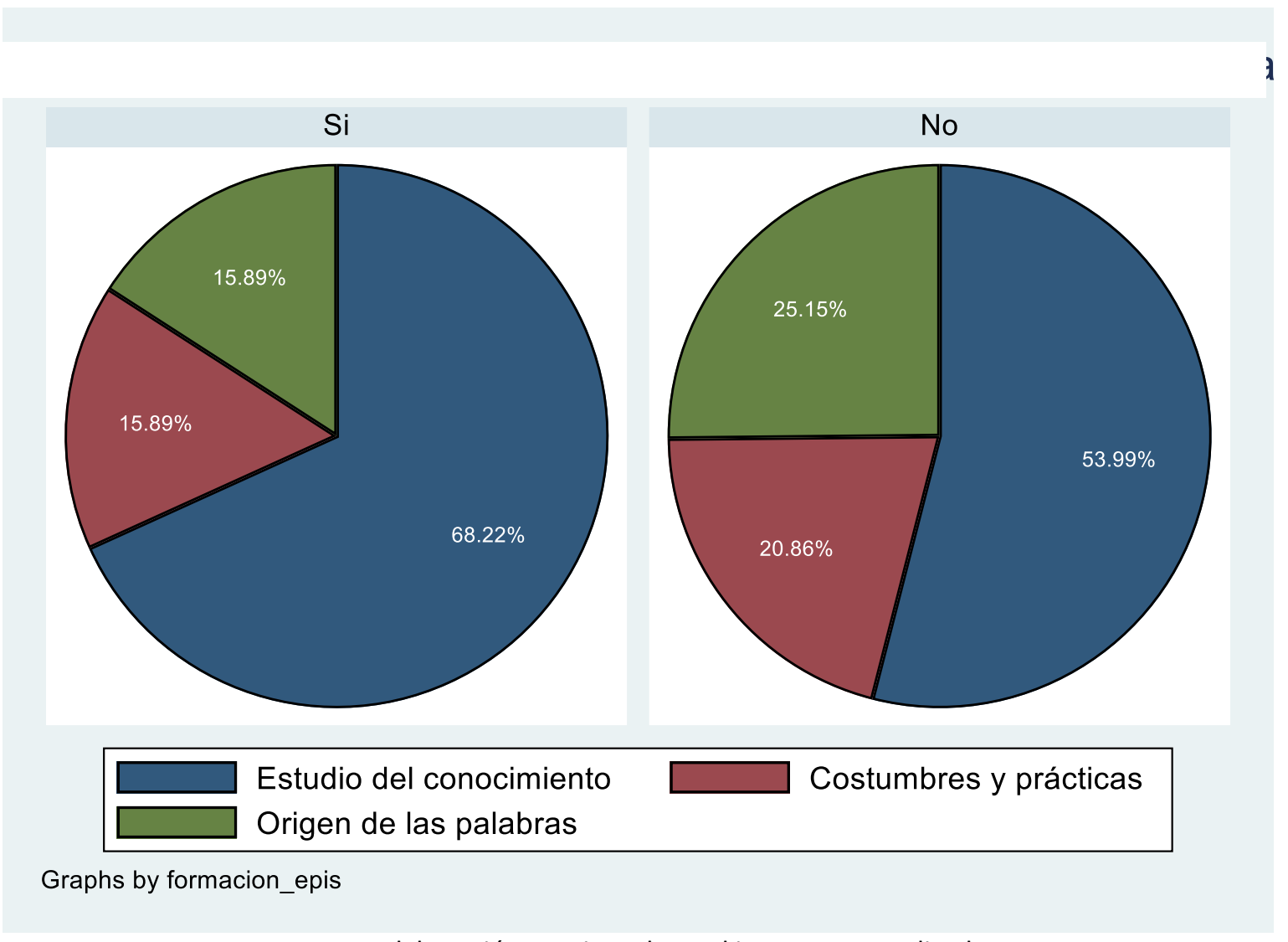

Fuente: Elaboración propia en base al instrumento aplicado

Al analizar el gráfico 3, evidentemente los estudiantes que afirmaron haber recibido formación epistemológicocontable durante su paso por la academia, acertaron en cuanto a la concepción de la palabra "epistemología", en comparación a quienes dijeron no haber recibido este tipo de formación. Sin embargo, es preciso señalar que más de el $30 \%$ de los estudiantes que respondieron haber recibido formación en cuanto a epistemología contable, respondieron erróneamente la pregunta cuatro, por lo que se presume, que ha sido un tema que no 
ha recibido la importancia que se merece en la formación de los estudiantes, debido a la confusión en los conceptos.

En el anexo 2 se evidencia que las respuestas obtenidas en la pregunta 13 no obedecen un patrón claro y las opiniones de los estudiantes están fuertemente divididas, sin embargo, la respuesta con mayor peso porcentual señala que a los estudiantes durante su formación académica se les ha hablado de teoría contable entre un 71 y $80 \%$ según los resultados del instrumento. Ahora bien, esto se puede contrastar con las respuestas obtenidas en la pregunta número 14, en el gráfico 4 se plasman los resultados de dicho interrogante:

\section{Gráfico 4}

Científicamente hablando una teoría:

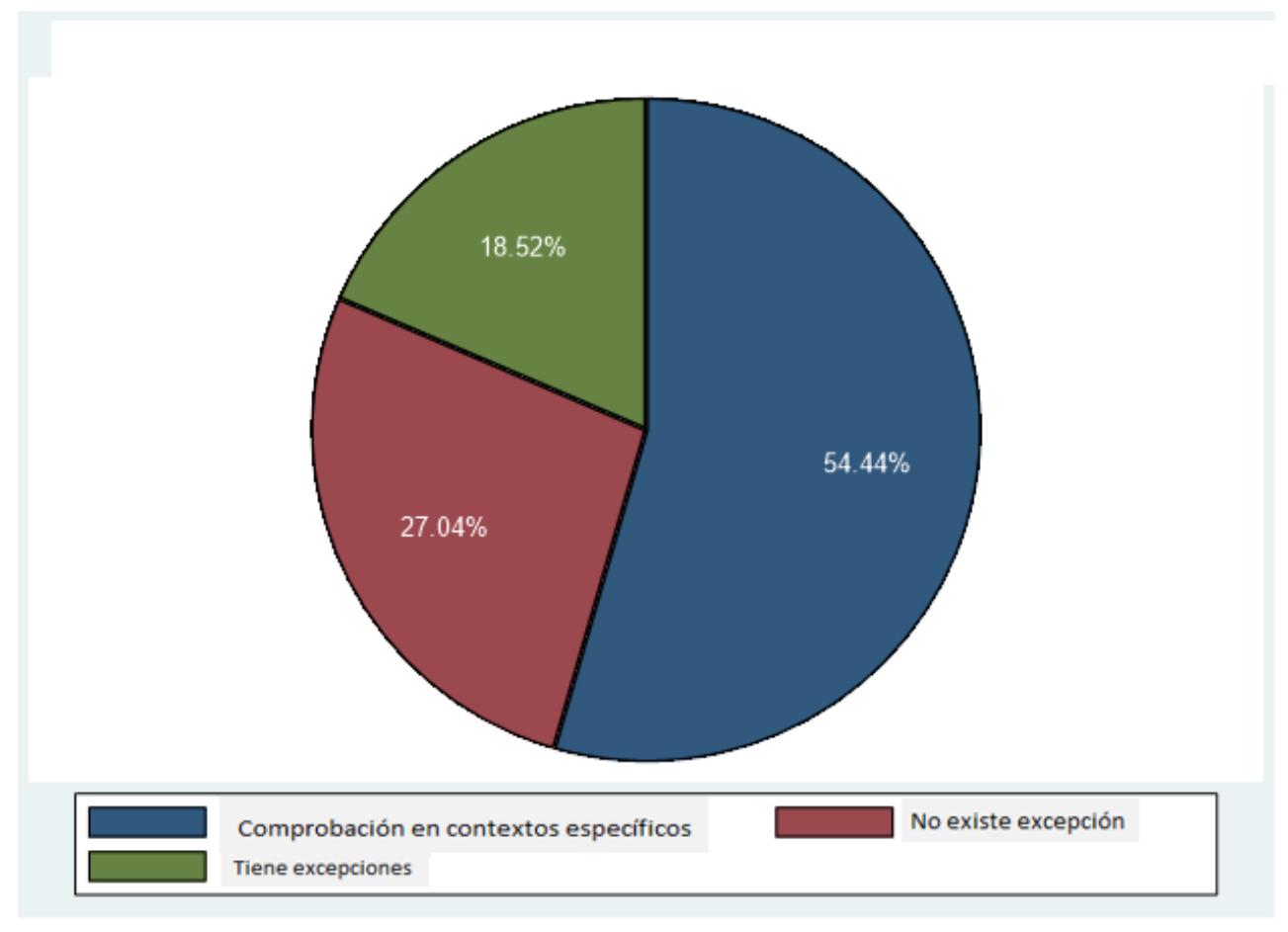

Fuente: Elaboración propia en base al instrumento aplicado

En el gráfico 4 se hace evidente como más de la mitad de los estudiantes saben que en ciencia una teoría tiene comprobación algunas veces, bajo contextos específicos; así, la respuesta correcta, obtuvo un porcentaje de 54,44\%; ahora bien, pese a que la mayoría de los estudiantes contestó de forma correcta a esta pregunta, sumando las respuestas marcadas de manera incorrecta se obtiene un importante 45,56\%, por esto es preciso señalar que al programa de contaduría pública le hace falta hacer más énfasis aclarando los términos de carácter teórico-científico.

\subsection{Imprecisiones respecto a los orígenes de la contabilidad}

Como señala Suárez (2008), Luca Pacioli no puede considerarse como el padre de la contabilidad, pues si bien es conocido como el autor de la partida doble, los orígenes de la contabilidad datan en la cultura Inca cuando mediante los QUIPUS se llevaban registros de carácter contable, aproximadamente en los años 8000 a.c. Pese a que en investigación contable varios autores señalan esteorigen, en la academia se enseña que Pacioli es el padre de la contabilidad, por lo que no es de extrañar los resultados obtenidos en las preguntas 6 y 8.

En ese sentido, el 58,89\% de los estudiantes, consideran erróneamente que Luca Pacioli fue quien invento la contabilidad, además el 61,85\% de los encuestados afirman que la contabilidad surge entre el año 1.400 y 1.500 d.C (Tiempo en el cual vivió Pacioli). Por la similitud en los resultados de estas dos preguntas se presumiría que 
los estudiantes que conciben a Pacioli como inventor de la contabilidad, afirman que la contabilidad surgió entre los siglos XV y XVI. En el gráfico 5 se aclara esto:

\section{Gráfico 5}

Surgimiento de la contabilidad segregado por Pacioli como inventor

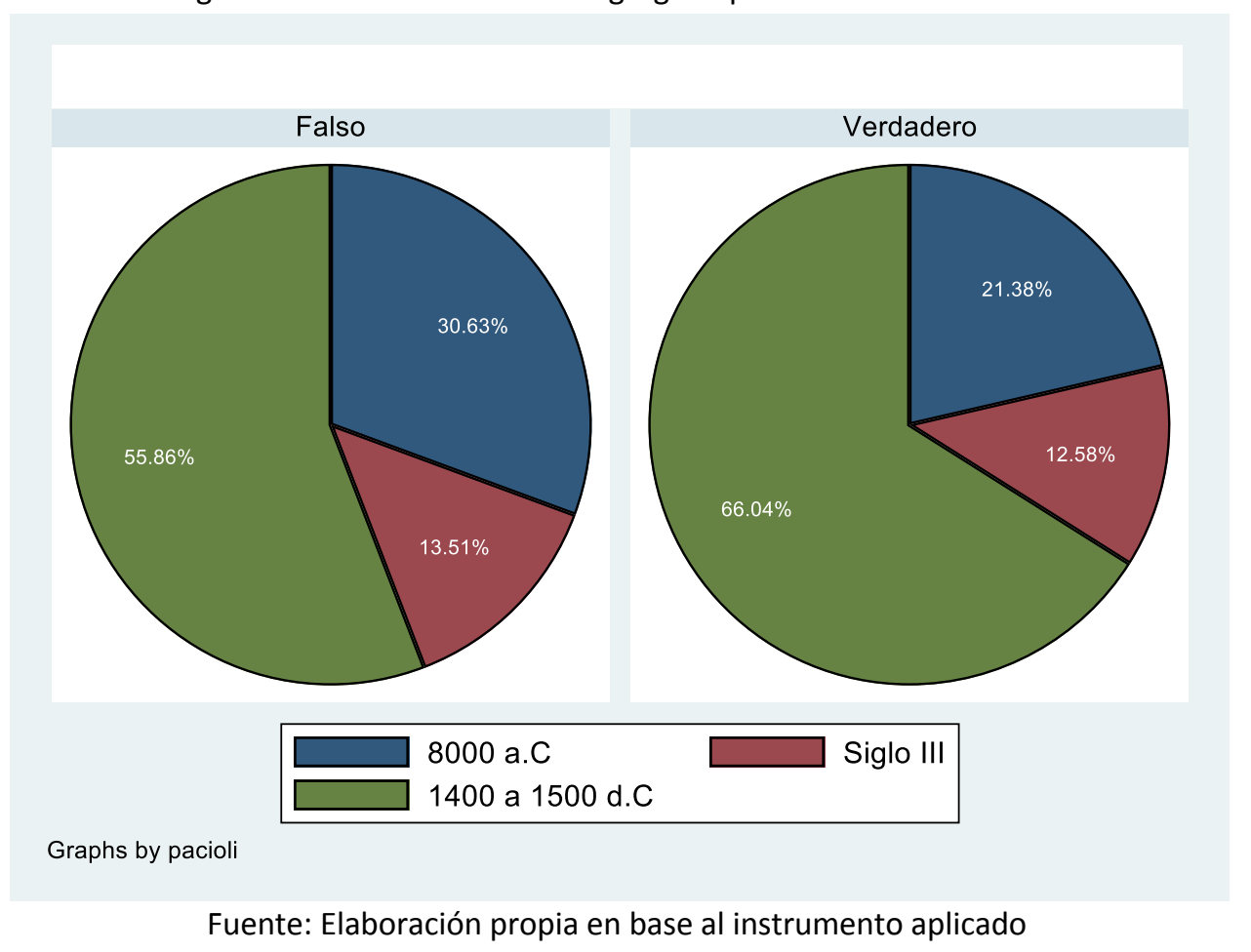

Analizando el gráfico 5, se hace evidente que tanto quienes respondieron que Pacioli es el inventor de la contabilidad, como quienes respondieron que no; en su mayoría afirman que la contabilidad nace entre los años 1.400 y 1.500 d.C., ignorando que su aparición tuvo lugar unos 8000 años A.C. en las antiguas civilizaciones indígenas.

\subsection{Relación entre falta de investigación y desarrollo del pensamiento contable}

Rueda (2007) afirma que uno de los principales problemas que tiene la falta de desarrollo del pensamiento contable y por tanto la falta de identidad respecto a los orígenes de la profesión, es la falta de interés por parte de la comunidad académica y profesional en la investigación, con el objetivo de indagar si se cumple lo señalado por Rueda (2007) en el caso de la Fundación Universitaria del Área Andina se formularon las preguntas 10 y 11. Cuando se pidió a los estudiantes que afirmaran el grado de importancia que tiene la investigación para la profesión contable, dando una calificación de 1 a 5, donde 1 es nada importante y cinco muy importante; el $94,08 \%$ de los estudiantes se mantuvieron en que la investigación era importante o muy importante para la profesión. Sin embargo, cuando se les preguntó, si harían parte de uno de los semilleros de investigación si el mismo no fuese opción de grado, se obtuvieron los resultados presentados en el gráfico 6: 


\section{Gráfico 6}

Semillerista voluntario segregado

por importancia de la investigación

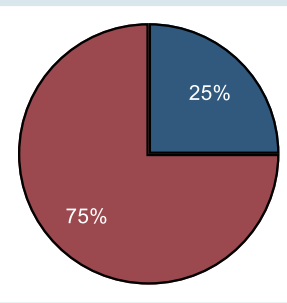

4

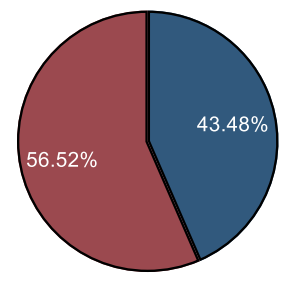

Graphs by import_invest
2

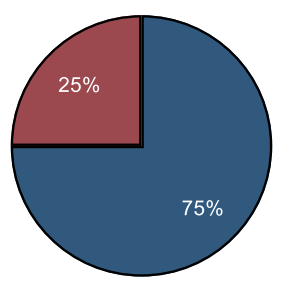

5

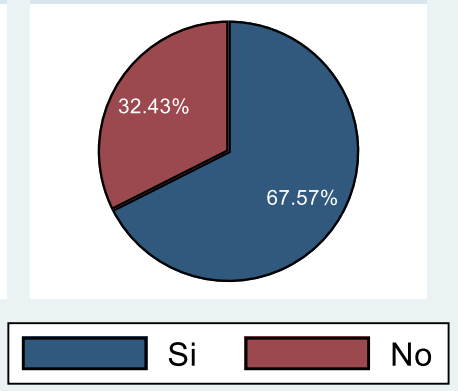

3

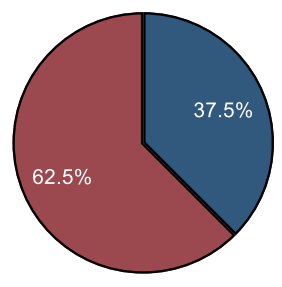

Fuente: Elaboración propia en base al instrumento aplicado

Analizando el gráfico 6, se evidencia como el 67,57\% de los estudiantes que afirman que la investigación es muy importante para la profesión contable, estarían dispuestos a participar de manera voluntaria en los semilleros de investigación, en el caso hipotético de que esta participación no fuese opción de grado. La contradicción está en quienes respondieron que la investigación era importante (opción 4) para la profesión, pues el 56,52\% de quienes se inclinaron por esta opción, afirman que no estarían dispuestos a participar de forma voluntaria en un semillero de investigación, si este no fuese opción de grado.

\section{Conclusiones}

El 68\% de los estudiantes de contaduría pública de la Fundación Universitaria del Área Andina, pese a cursar una carrera de carácter profesional, concibe la contabilidad como una técnica dedicada simplemente a llevar registros contables de carácter financiero, desconociendo el ámbito teórico planteado por varios autores. Un aspecto que influye en los resultados obtenidos es el hecho de que en el programa de Contaduría Pública no se contemplan asignaturas que traten el tema central de la presente investigación; el llamado es a los directivos de las facultades y programas de pregrado con tendencias similares, para evaluar la posibilidad de incluir asignaturas que hablen de epistemología y el desarrollo del pensamiento contable; a su vez, esto se puede articular con la integración de estudiantes a los semilleros, pues precisamente desde el área de investigación es donde se puede construir conocimiento, plantear nuevos conceptos y temas de discusión. En tal sentido se propone trabajar para que, por medio del estudio de teoría contable, se construya un pensamiento crítico respecto la función del contador público en la sociedad y nos apartemos paulatinamente de la visión actual, que es la de estar formando profesionales para simplemente seguir procedimientos.

Frente a lo planteado por Rueda Delgado (2007), es preciso afirmar que, en la Fundación Universitaria del Área Andina, ocurre lo contrario, pues el 95\% de los estudiantes conciben la investigación como muy importante o 
importante para la profesión, por lo que en este caso nos encontramos con una relación inversa entre falta de importancia que se le da a la investigación y la falta del desarrollo del pensamiento contable. Sin embargo, existe la limitante de la contradicción que se presenta en el gráfico 6.

Así mismo, es importante señalar la necesidad de fortalecer la estructura curricular y los contenidos, con elementos claves del ámbito teórico, como lo son la interdisciplinariedad y las posibilidades que ofrece a la disciplina y a la sociedad las posturas teóricas heterodoxas, es decir, en un ejercicio de honestidad intelectual señalar que la contabilidad financiera no es la contabilidad, sino que es una de las opciones, la dominante, la más aceptada; pero de ninguna manera única, la contabilidad social y la contabilidad ambiental son claros ejemplos de tal situación.

\section{Referencias bibliográficas}

Ariza Angarita, Y., \& Villasmil Molero, M. (2014). TEORÍA CONTABLE: FUNDAMENTO DE ANÁLISIS EN EL EJERCICIO PROFESIONAL Y LA PRÁCTICA PEDAGÓGICA. Desarrollo gerencial, 6(2), 41-71.

Cañibano, L., Tua Pereda, J., \& López, J. (1985). Naturaleza y filosofía de los principios contables. Revista española de financiación y contabilidad(47), 293-355.

Carrizo, W., \& León, S. (2007). ¿Qué realidad representa la contabilidad? Pecunia(5), 17-27.

Casal, R. A., Viloria, N., \& Zaá Méndez, J. R. (2005). Las fronteras de la corporalidad como rasgo epistemológico de la Ciencia Contable. Actualidad Contable Faces, 8(11), 15-19.

Casal, R., \& Viloria, N. (2007). La Ciencia Contable, Su historia, filosofía, evolución y su producto. Actualidad Contable FACES, 10(15), 19-28.

De la Rosa Leal, M. E. (2016). La epistemología contable medioambiental, un análisis prospectivo. Mercados y Negocios, 15(8), 18-43.

García Duque, C. E. (2009). ¿Qué significa hacer "pensamiento contable"? Elementos para la comprensión de algunos problemas teóricos involucrados en tal actividad. Lumina 10(10), 98-114.

Geba, N. (2004). Contabilidad como disciplina científica, sus especialidades social y financiera. ¿Una ruptura epistemológica? Obtenido de amazonaws.com:

https://s3.amazonaws.com/academia.edu.documents/34456698/Geba-

_CONTABILIDAD_COMO_DISCIPLINA_CIENTIFICA_SUS_ESPECIALI.pdf?response-contentdisposition=inline\%3B\%20filename\%3DGeba_CONTABILIDAD_COMO_DISCIPLINA_CIENTI.pdf\&X-AmzAlgorithm=AWS4-HMAC-SHA256\&X-A

Gómez Villegas, M. (2004). BREVE INTRODUCCIÓN AL ESTADO DEL ARTE DE LA ORIENTACIÓN CRÍTICA EN LA DISCIPLINA CONTABLE. Contaduría Universidad de Antioquia(45), 113-132.

Gómez Villegas, M. (2008). Dinámica de la concepción y la enseñanza de la teoría contable en Colombia (19702000): Una exploración institucional. Documentos FCE. Escuela de Administración de Empresas y Contaduría Pública(3), 1-40.

Gonzalez Santos, L. A. (2014). Fundamentación conceptual de la crisis contable. REVISTA INTERNACIONAL LEGIS DE CONTABILIDAD \& AUDITORÍA, 21, 151-192.

Machado Rivera, M. A. (2012). Del positivismo a la diversidad epistemológica: un paso necesario para la construcción de pensamiento contable. Contaduría Universidad de Antioquia(60), 219-237. 
Mancilla Yangali, J. C., \& Quispe Goya, K. C. (2017). LAS DOCTRINAS CONTABLES Y EL CONOCIMIENTO CIENTIFICO EN LA ESCUELA PROFESIONAL DE CONTABILIDAD, UNIVERSIDAD NACIONAL DE HUANCAVELICA, 2017. Obtenido de Repositorio Institucional Universidad Nacional de Huancavelica: http://repositorio.unh.edu.pe/handle/UNH/2400

Matías González, A., \& Hernández Alegría, A. (2014). POSITIVISMO, DIALÉCTICA MATERIALISTA Y FENOMENOLOGÍA: TRES ENFOQUES FILOSÓFICOS DEL MÉTODO CIENTÍFICO Y LA INVESTIGACIÓN EDUCATIVA. Actualidades Investigativas en Educación, 14(3), 1-20.

Mejía Soto, E. (2004). Introducción al pensamiento contable de Richard Mattessich. REVISTA INTERNACIONAL LEGIS DE CONTABILIDAD \& AUDITORÍA, 135-174.

Mejía Soto, E., Mora Roa, G., \& Montes Salazar, C. (2013). Aproximación crítica a la función contable desde la teoría tridimensional de la contabilidad. Lúmina(14), 142-175.

Ordoñez Norena, S. L. (6-8 de Junio de 2008). Contra el adiestramientio contable: Invitación a la ruptura epistemológica en la formación del contador público. Perspectivas críticas de la contabilidad "Reflexiones y críticas contables alternas al pensamiento único", 117-126.

Rueda Delgado, G. (2007). La investigación contable: vínculos ontológicos y las posibilidades de la investigación interpretativa. Contaduría Universidad de Antioquia(50), 119-132.

Suárez Pineda, J. A. (2012). Benedetto Cotrugli Raugeo: Padre de la gestión moderna. TEUKEN BIDIKAY. Revista Latinoamericana de Investigación en Organizaciones, Ambiente y Sociedad, 3(3), 100-120.

Suárez Pineda, J. (2008). Momentos estelares de la Contabilidad. Bogotá: Ediciones Grancolombianas Universidad La Gran Colombia.

Torres Bardales, C., \& Lam Wong, A. (2012). Los fundamentos epistemológicos de la contabilidad y su incidencia en la formación competitiva del contador público. Sotavento M.B.A(19), 32-50.

Anexos

Anexo 1. Encuesta a estudiantes de contaduría de la FUAA

\section{FECHA:}

OBJETIVO: La presente encuesta se realiza de manera ANÓNIMA, el objetivo de esta es aportar a los resultados de una investigación en curso llevada a cabo por el estudiante Camilo Andres Baron Pinto, perteneciente al semillero Contabilidad Ambiental y Responsabilidad Social Empresarial.

1. ¿Con cuál de los siguientes conceptos se relaciona la contabilidad?

a) Ciencia factual dedicada a la compresión de la realidad por medio de procedimientos técnicos.

b) Tecnología social que mide la realidad.

c) La contabilidad es una técnica para medir recursos económicos. 
2. La contabilidad:

a) Se apoya en actividades económicas para proveer la información.

b) Genera conocimientos entre la economía y las finanzas.

3. En su formación académica, ¿le han hablado de epistemología contable?
a) $\mathrm{Si}$
b) No

4. La epistemología tiene que ver con:

a) Las costumbres y prácticas cotidianas.

b) El estudio del conocimiento.

c) Origen de las palabras.

5. La contabilidad se dedica a:

a) Cumplir las NIIF, NIC y demás normatividad; mediante los respectivos procedimientos.

b) Identificar y resolver problemas locales y externos, aplicando conocimientos propios.

6. Luca Pacioli es el inventor de la contabilidad:
a) Verdadero
b) Falso

7. Originariamente ¿Qué es QUIPUS?

8. La contabilidad nace aproximadamente en los años:
a) 1400 a 1500 d.C
b) Siglo III
c) 8000 a.C

9. Luca Pacioli fue:
a) Economista
b) Matemático
c) Gramático 
10. ¿Qué grado de importancia considera que tiene la investigación para la profesión contable? Siendo cinco la más importante y uno la menos relevante.

\begin{tabular}{|l|l|l|l|l|}
\hline $\mathbf{1}$ & $\mathbf{2}$ & $\mathbf{3}$ & $\mathbf{4}$ & $\mathbf{5}$ \\
\hline & & & & \\
\hline
\end{tabular}

11. Si el semillero de investigación no fuese opción de grado. ¿Participaría usted en el mismo?
a) $\mathrm{Si}$
b) No

12. En su formación académica sus docentes, coordinadores y demás. ¿Lo han alentado para su participación en semilleros de investigación?
a) $\mathrm{Si}$
b) No

13. Durante su formación académica, ¿en qué porcentaje considera que se le ha hablado de teoría contable?

\begin{tabular}{|l|l|l|l|l|l|l|l|l|l|}
\hline $0-10 \%$ & $11-20 \%$ & $21-30 \%$ & $31-40 \%$ & $41-50 \%$ & $51-60 \%$ & $61-70 \%$ & $71-80 \%$ & $81-90 \%$ & $91-100 \%$ \\
\hline & & & & & & & & & \\
\hline
\end{tabular}

14. Científicamente hablando, una teoría:

a) Se cumple la mayoría de las veces, tiene excepciones.

b) Tiene comprobación algunas veces y bajo contextos específicos.

c) Es una hipótesis probada en donde no existe excepción.

Anexo 2. Resultados de encuesta

\begin{tabular}{|c|c|c|c|}
\hline Pregunta & Respuesta & Sumatoria & Promedio \\
\hline \multirow[t]{3}{*}{1} & $\begin{array}{l}\text { Ciencia factual dedicada a la compresión de la realidad con } \\
\text { procedimientos }\end{array}$ & 81 & $30 \%$ \\
\hline & Tecnología social que mide la realidad. & 6 & $2 \%$ \\
\hline & $\begin{array}{l}\text { La contabilidad es una técnica para medir recursos } \\
\text { económicos. }\end{array}$ & 183 & $68 \%$ \\
\hline \multirow[t]{2}{*}{2} & Se apoya en actividades económicas para proveer información. & 155 & $57 \%$ \\
\hline & Genera conocimientos entre la economía y las finanzas. & 115 & $43 \%$ \\
\hline \multirow[t]{2}{*}{3} & Sí & 107 & $40 \%$ \\
\hline & No & 163 & $60 \%$ \\
\hline 4 & Las costumbres y prácticas cotidianas. & 51 & $19 \%$ \\
\hline
\end{tabular}




\begin{tabular}{|c|c|c|c|}
\hline & El estudio del conocimiento. & 161 & $60 \%$ \\
\hline & Origen de las palabras. & 58 & $21 \%$ \\
\hline \multirow[t]{2}{*}{5} & $\begin{array}{l}\text { Cumplir las NIIF, NIC y demás normatividad, mediante } \\
\text { procedimientos. }\end{array}$ & 220 & $81 \%$ \\
\hline & Genera conocimientos entre la economía y las finanzas. & 50 & $19 \%$ \\
\hline \multirow[t]{2}{*}{6} & VERDADERO & 159 & $59 \%$ \\
\hline & FALSO & 111 & $41 \%$ \\
\hline \multirow[t]{2}{*}{7} & Correcto & 87 & $32 \%$ \\
\hline & Incorrecto & 183 & $68 \%$ \\
\hline \multirow[t]{3}{*}{8} & 1400 a 1500 d.C & 167 & $62 \%$ \\
\hline & Siglo III & 35 & $13 \%$ \\
\hline & 8000 a.C & 68 & $25 \%$ \\
\hline \multirow[t]{3}{*}{9} & Economista & 118 & $44 \%$ \\
\hline & Matemático & 144 & $53 \%$ \\
\hline & Gramático & 8 & $3 \%$ \\
\hline \multirow[t]{5}{*}{10} & 1 & 4 & $1 \%$ \\
\hline & 2 & 4 & $1 \%$ \\
\hline & 3 & 8 & $3 \%$ \\
\hline & 4 & 69 & $26 \%$ \\
\hline & 5 & 185 & $69 \%$ \\
\hline \multirow[t]{2}{*}{11} & Sí & 162 & $60 \%$ \\
\hline & No & 108 & $40 \%$ \\
\hline \multirow[t]{2}{*}{12} & Sí & 218 & $81 \%$ \\
\hline & No & 52 & $19 \%$ \\
\hline \multirow[t]{7}{*}{13} & $0-10 \%$ & 4 & $1 \%$ \\
\hline & $11-20 \%$ & 5 & $2 \%$ \\
\hline & $21-30 \%$ & 17 & $6 \%$ \\
\hline & $31-40 \%$ & 24 & $9 \%$ \\
\hline & $41-50 \%$ & 35 & $13 \%$ \\
\hline & $51-60 \%$ & 36 & $13 \%$ \\
\hline & $61-70 \%$ & 45 & $17 \%$ \\
\hline
\end{tabular}




\begin{tabular}{|c|c|c|c|}
\hline & $71-80 \%$ & 62 & $23 \%$ \\
\hline & $81-90 \%$ & 36 & $13 \%$ \\
\hline & $91-100 \%$ & 6 & $2 \%$ \\
\hline \multirow[t]{3}{*}{14} & Se cumple la mayoría de las veces, tiene excepciones. & 50 & $19 \%$ \\
\hline & $\begin{array}{l}\text { Tiene comprobación algunas veces y bajo contextos } \\
\text { específicos. }\end{array}$ & 147 & $54 \%$ \\
\hline & Es una hipótesis probada en donde no existe excepción. & 73 & $27 \%$ \\
\hline
\end{tabular}

Esta obra está bajo una Licencia Creative Commons Attribución-NoCommercial 4.0 International

(cc) EY-NC 